\title{
Mezuniyet Öncesi Tıp Eğitiminde Program Çıktılarının Güncellenmesi: Yeditepe Üniversitesi Tıp Fakültesi Süreci
}

\section{Revising Program Outcomes in Undergraduate Medical Education: Yeditepe University, Faculty of Medicine Process}

\author{
Özdemir $S^{\prime}$, Acuner $C^{2}$, Akalın A.A. ${ }^{1}$, Tanriöver $\ddot{O}^{\prime}$, İzbrak $G^{\prime}$, Ercan $S^{3}$ \\ ${ }^{1}$ Yeditepe Üniversitesi Tıp Fakültesi, Tıp Eğitimi Anabilim Dalı, \\ ${ }^{2}$ Yeditepe Üniversitesi Tıp Fakültesi, Mikrobiyoloji Anabilim Dalı, \\ ${ }^{3}$ Yeditepe Üniversitesi Tıp Fakültesi, Göğüs Cerrahisi Anabilim Dalı
}

Anahtar Sözcükler:

Çıktıya dayalı eğitim,

Program çıktıları,

Yeterlikler

Keywords:

Outcome based education,

Program outcomes,

Competencies

Gönderilme Tarihi

Submitted:16.05.2018

Kabul Tarihi

Accepted: 09.07.2018

\section{ÖZET:}

Amaç: Bu çalışmanın amacı, Yeditepe Üniversitesi Tıp Fakültesi, Mezuniyet Öncesi Tıp Eğitimi Program Çıktıları Revizyon sürecinin tanıtılması ve bu süreçte elde edilen deneyimlerin paylaşılmasıdır.

Yöntem: Revizyon sürecinde ilk olarak Bologna Eşgüdüm Kurulu, Tip Fakültesi Danışma Komisyonu (BEK-DK) üyesi 5 öğretim üyesinin katılımıyla bir çekirdek grup (BEK-DK Uzlaşı Grubu) oluşturulmuştur. $\mathrm{Bu}$ grup revizyon sürecinde yapılacak çalışmaları BEK-DK adına sürdürme görevi üstlenmiştir. Uzlaşı Grubu'nun revizyon sürecindeki amacı; sağlık hizmeti bağlamında toplum yönelimli, hasta hekim ilişkisi bağlamında hasta merkezli bir yaklaşımla YÜTF Program Çıktıları (YÜTF-PÇ) 2011'i gözden geçirmek ve YÜTF-PÇ 2015'i oluşturmak için doküman üretmektir.

Grubun çalışma yöntemlerini ise, a) Küçük ve büyük grup tartışmaları, b) Süreçten sürekli bilgilendirme c) Oluşturulan belgeler için yazılı görüş isteme, d) Anketle veri toplama ve e) Çalıştay oluşturmuş̧ur.

Bulgular: 14 PÇ yeterlik yazım kurallarına göre yeniden düzenlenmiş, 3 PÇ fiillerinde değişiklik yapılmış ve 25 PÇ aynen korunmuştur. Program çıktılarının ana çatısı, "hekimin mesleğini icra ederken sahip olması gereken özellikler neler olmalıdır?" sorusundan yola çıkarak, üç başlık altında toplanmıştır. Bunlar; hekimin sahip olması gereken temel donanımlar, değerler ve yaklaşımlar ile kişisel gelişimini sürdürmesi için sahip olması gereken özdeğerlerdir.

Tartışma ve Sonuç: YÜTF Program Çıktıları, iç ve dış paydaşların etkin katılımı ile hekimden güncel beklentiler ve toplumun sağlık beklentilerinde yaşanmakta olan değişiklikler bağlamında gözden geçirilmiştir. Bu revizyon çalışması hem yeterliklerin kurallara uygun olarak yazılması yönünden 
teknik bir süreci hem de içeriğe ilişkin düzenlemeleri kapsamaktadır. Sürecin başında amaçlanan, sağlık hizmeti bağlamında toplum yönelimli, hasta hekim ilişkisi bağlamında ise hasta merkezli ve biyopsikososyal yaklaşım, program çıktılarının arka planını oluşturmuştur.

\section{MAKALE KÜNYE BİLGÍSİ}

- Özdemir, S., Acuner, İ. Ç., Akalın, A. A., Tanrı̈ver, Ö., İzbırak, G., \& Ercan S. (2018). Mezuniyet Öncesi Tıp Eğitiminde Program Çıktılarının Güncellenmesi: Yeditepe Üniversitesi Tıp Fakültesi Süreci. Tıp Eğitimi Dünyas1, (17)52, 76-93.

\section{ABSTRACT:}

Aim: The aim of this study is to introduce the revision process of Yeditepe University Faculty of Medicine (YUFM) Program Outcomes (POs) and to share the experience gained in this process.

Material: In the revision process, a core consensus group of five faculty members selected from Advisory Commission of the Bologna Coordination Committee, (BCC-AC) was formed. This group undertook the work to be done during the revision process on behalf of $B C C$ AC. The working methods of the group are as follows: a) Small and large group discussions b) Continuous information sharing on the process c) Requesting written opinions for the created documents d) Data collection by questionnaire and e) Workshop.

Results: Fourteen of the POs have been rearranged according to the qualification writing rules. Three of the POs have been changed in their actions. Twenty five POs remained unchanged. The main frame of the program outcomes included three headings, on the basis of answers to the question; "What should the physician have to do when he / she carries out his / her occupation?" The headings are; 1. the basic qualifications that the physician should possess 2. values and approaches 3. self-values that must be possessed to maintain personal development.

Conclusion: The Program Outcomes of the YUFM have been revised with the active involvement of internal and external stakeholders. In this revision context, the current expectations from the physician and the changes in the health expectancies of the community have been described. This revision study has been realised both as a technical process and content arrangements. While community-oriented practice has been embraced in the context of healthcare services, the patient-centered and biopsychosocial approach has been adopted in the context of patient-physician relationship, as a background of program outcomes.

\section{GíRiş}

Çıktıya Dayalı Eğitim, eğitim programının, öğrencilerin programın sonunda sergileyecekleri özelliklere göre düzenlendiği bir eğitim yaklaşımıdır. Çıktıya Dayalı Eğitim "sonuç odaklı düşünme" olarak özetlenebilir. Çıktılar, eğitim programı içerisinde neyin öğretileceğine ve neyin değerlendirileceğine k1lavuzluk eder (1). Hekim yeterlikleri, dünya genelinde artarak, tıp eğitiminin her düzeyi için odak noktası haline gelmiştir (2). $\mathrm{Bu}$ yeterliklerin hekim adayı öğrenciler tarafından kazanılması için, program çıktılarının net olarak belirlenmesi, eğitimle ilgili tüm taraflara duyurulması ve eğitim programının tüm bileşenlerinin bu çıktılara göre düzenlenmesi gerekmektedir. Birçok tıp fakültesi kendi eğitim programları için çıktılar tanımlamışlardır $(3,4,5)$.

Yeditepe Üniversitesi T1p Fakültesi (YÜTF) Mezuniyet Öncesi Eğitim Programının 
(MÖTEP) amac1; Türkiye'nin ve dünyanın sağlık sorunlarını bilen ve birinci basamakta sağlık hizmet sunumunu ve yönetimini yapabilecek yeterlilikte bilgi, beceri ve tutumlarla donanmış, mesleğin etik kurallarını bilen, gözeten ve uygulayan, ulusal ve uluslararası düzeyde güncel bilgilere açık, sistematik düşünebilen, araştırıcı ve sorgulayıcı, kendisini sürekli yenileyip geliştiren, ekip çalışması yapabilen, tıp bilimi ve ilgili alanlarda teknolojiyi iyi kullanan, etkin iletişim becerilerine ve toplum lideri niteliklerine sahip hekimler yetiştirmektir. YÜTF Program Çıktıları, bu amaca yönelik olarak, Bologna süreci kapsamında Bologna Eşgüdüm Kurulu Tıp Fakültesi Danışma Komisyonu'nun (BEK-DK) çalışmaları ile, 2011 yılında oluşturulmuştur. 2011 program çıktılarının güncellenmesi aşağıdaki gereklilikler nedeni ile gerçekleştirilmiştir.

1. YÜTF, BEK-DK Yönergesi: Yönerge belli aralıklarla program çıktılarının revizyonunu öngörmektedir.

2. Ulusal Çekirdek Eğitim Programı (UÇEP) 2014: UÇEP 2014 uyum çalışmaları kapsamında yeterlik alanlarına yönelik bir yapılanma önermektedir.

3. Toplumun sağlık ihtiyaçlarındaki değişiklikler: Toplumun sağlı hizmetlerinden beklentilerindeki olası değişikliklerin tespit edilip bunların mezun hekimlerin yeterlik alanlarına uyarlanması, tıp eğitiminde program geliştirmenin gerekliliklerden birini oluşturmaktadır.

4. Dünyada mezun hekimlerden beklentilerin değişmesi: Program çıktılarının güncel uluslararası dokümanlarla karşılaştırılıp kendi eğitim programımızın bu açıdan değerlendirilmesi, çıktıların gözden geçirilmesinin gerekliliklerinden bir diğerini oluşturmaktadır.

\begin{abstract}
AMAÇ
Bu çalışmanın amacı, Yeditepe Üniversitesi Tıp Fakültesi Program Çıktıları gözden geçirilme sürecinin aktarılması ve bu süreçte elde edilen deneyimlerin paylaşılmasıdır.
\end{abstract}

\section{YÖNTEM}

Program çıktılarının gözden geçirilme süreci, Yeditepe Üniversitesi Bologna Eşgüdüm Kurulu TıpFakültesiDanışmaKomisyonu'nun(YÜBEK - TFDK) yürütücülüğünde gerçekleşmiştir. YÜBEK-TFDK iç paydaş temsilcileri ve seçilmiş dış paydaş katılımı ile oluşturulmuş bir komisyondur. İç paydaş temsilcileri (eğitimi verenler ve alanlar), 21 YÜTF öğretim üyesi ve 6 YÜTF öğrencisinden oluşmaktadır. Dış paydaşlar (eğitimin sonucundan etkilenenler) ise tıp eğitimi ve sağlık hizmeti sunumunun tüm taraflarını kapsayacak şekilde kurumsal 


\section{Tablo 1. Yeditepe Ūniversitesi Bologna Süreci Danıșma Kurulu Kurum-dıșı Paydaşları}

1. İstanbul Anadolu Kuzey Kamu Hastaneleri Birligi Kurumu

2. Sağlık Bakanlığı İstanbul Halk Sağlığı Mūdūrlūgü

3. Yükseköğretim Kurulu, Avrupa Birliği ve Uluslararası İlişkiler Birimi

4. Yükseköğretim Kurulu, Yükseköğretim Kurullarında Akademik Değerlendime ve Kalite Geliștirme Kurulu (YŌDEK)

5. Yükseköğretim Kurulu, Türkiye ENIC/NARIC Merkezi

6. T.C. Kalkınma Bakanlığı

7. Avrupa Birliği Eğgitim ve Gençlik Programları Merkezi Başkanlığı (Diploma Eki/AKTS Etiketi için Ulusal Ajans)

8. Yükseköğretim Kurulu, Tıp Fakülteleri Ulusal Çekirdek Eğitim Programı Sorumlu Birimi

9. Türk Tabipler Birligi (TTB), İstanbul Tabip Odası

10. TTB-Genel Pratisyenlik Enstitüsū

11. TTB-Uzmanlik Dernekleri Koordinasyon Kurulu

12. Aile Hekimliği Akademisi (TAHAD)

13. Aile Hekimliği Eğitim ve Araștımna Derneği (AHEAD)

14. Türkiye Aile Hekimleri Uzmanlık Derneği (TAHUD)

15. Halk Sağlığ Uzmanlan Derneği (HASUDER)

16. Tıp Egitimi Değerlendirme ve Akreditasyon Demeği (TEPDAD)

17. Ulusal Tıp Eğitimi Akreditasyon Kurulu (UTEAK) Danıșmalık ve Eğitim Komisyonu (DEK)

18. Tıp Eggitimini Geliștirme Derneği (TEGED)

19. Türk Tıp Eg̈itimi Derneği

20. Yeditepe Üniversitesi Tıp Fakültesi Mezunlan Demeği

21. Hasta ve Hasta Yakını Hakları Derneği (HAYAD)

22. Hasta Hakları Aktivistleri Demeği

23. Özel Hastaneler ve Sağlık Kuruluşları Demeği (OHSAD)

24. Tibbi Malzeme ve Cihaz Ūreticileri Derneği (TÜDER) 
olarak belirlenmiştir. Bu taraflar; Türkiye'de yükseköğretimin merkezi uygulayıcısı kurumlar, tıp eğitiminin geliştirilmesi ve değerlendirilmesi ile ilgili dernekler, mezun hekim dernekleri, sağl1k hizmeti sunucusu kamu ve özel kurum ve kuruluşlar, hekimlik meslek örgütleri, birinci basamak sağlık hizmetine yönelik dernekler, hasta, hasta yakınları ve hasta aktivistlerinin oluşturduğu derneklerdir. Bu bağlamda toplam 24 kurumsal dış paydaş (Tablo1.)

\section{YÜBEK-TFDK üyesi olarak belirlenmiştir.} Kurumsal diş paydaşlara ilgili resmi yazılar Yeditepe Üniversitesi Rektörlüğü tarafından gönderilmiştir. Ayrıca telefon ve e-posta yoluyla kurumlarla iletişim kurularak dış paydaş olarak katılım arttırılmaya çalışılmıştır. Kurumsal dış paydaşlarla ve süreç içinde belirlenen temsilcilerle iletişimin sürekli kılınması ve süreçten sürekli bilgilenme almaları için çaba sarfedilmiştir.

Gözden geçirme süreci Aralık 2014'te başlamıştır. İlk olarak BEK-DK iç paydaşlardan 5 öğretim üyesinden oluşan bir çekirdek grup (BEK-DK Uzlaşı Grubu) oluşturulmuştur. Beş öğretim üyesinden dördü Tıp Eğitimi Anabilim Dalı mensubu bir diğeri ise Mikrobiyoloji Anabilim Dalı mensubu olup Tip Fakültesi Bologna Komisyonu başkanı ve uzun zaman eğitim öğretim, kurul ve komisyonlarında görev almış deneyimli bir akademisyendir. $\mathrm{Bu}$ grup revizyon sürecinde yapılacak çalışmaları BEKDK adına sürdürme görevi üstlenmiştir. BEKDK Uzlaşı Grubu'nun (BEK-DK-UG) revizyon sürecindeki amacı ve hedefleri şunlardır;

Amaç: YÜTF Program Çıktılarının (YÜTF-PÇ 2011) ilk oluşturulması sırasında ilke edinilen, sağlık hizmeti bağlamında toplum yönelimli, hasta hekim ilişkisi bağlamında hasta merkezli, yaklaşıma bağlı kalarak bu çıktıları revize etmek, bu revizyonda iç ve dış paydaşların katılımını sağlayıcı etkinlikler düzenlemek ve nihai olarak YÜTF-PÇ 2015'in yazılmasını sağlamaktır.

\section{Hedefler:}

1. Gözden geçirme ve düzeltme; YÜTF-PÇ 2011'in gerek varsa sadeleştirilmesi, yeterlik yazımına uygun olarak yeniden yazılması, UÇEP 2014'ün önerdiği yeterlikler çerçevesine uygun hale getirilmesi (BEK-DK-UG Hedef 1.). 2. İhtiyaç belirleme ve güncelleme; YÜTF Program Çıktıları 2011'in (YÜTF-PÇ 2011) Ulusal ve Uluslararası dokümanlarla karşılaştırılması, mezun hekimden beklentilerin analiz edilmesi (BEK-DK-UG Hedef 2.).

Grubun çalışma yöntemlerini ise şunlar oluşturmuştur:

1. Küçük ve büyük grup tartışmaları.

2. Süreçten sürekli bilgilendirme.

3. Oluşturulan dokümanlar için yazılı görüş isteme

4. Anketle veri toplama

5. Çalıştay

\section{SÜREÇ:}

Süreç, hedefler bağlamında program çıktılarının aşama aşama geliştirilmesi ile devam etmiştir (Şekil 1.).

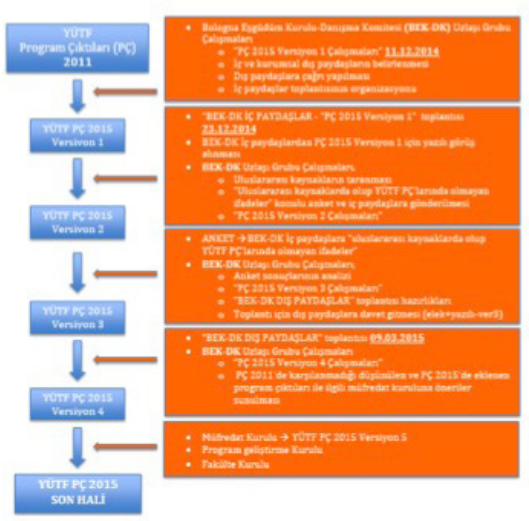

Şekil 1. YOTF PC- 2015 Revizyon Süred 


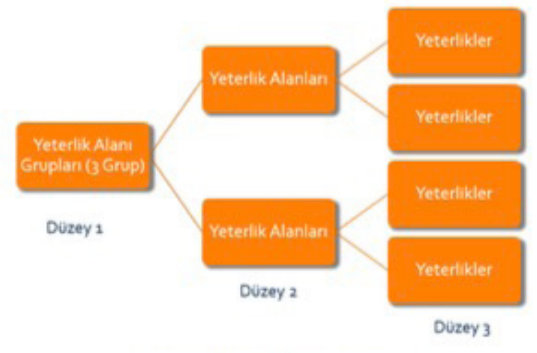

Şekil 2. YOTF PC-2015 3 düzeyli bir yapulanmast

A. YÜTF-PÇ 2015 Versiyon 1.0 Çalışmaları:

a. Küçük Grup Tartışmaları: BEK-DK-UG Hedef 1. bağlamında gözden geçirme ve düzeltme için BEK-DK Uzlaşı Grubu öncelikle küçük grup tartışmaları ile YÜTF- PÇ 2011 üzerine çalışmalara başlamıştır. 2014 yılı Aralık ayı içinde 3-5 öğretim üyesinin katılımı ile gerçekleştirilen, 2-3 saat süren 5 toplantı ile YÜTF-PÇ 2015 Versiyon 1.0 ortaya çıkmıştır. Versiyon 1.0 YÜTF PÇ 2011'e göre sadeleştirilmiş ve yeterlik yazım kurallarına göre bazı değişikliklere uğramıştır. Versiyon 1.0'ın YÜTF-PÇ 2011'den en büyük fark1 program çıktılarına 3 düzeyli bir yapılanma (Şekil 2.) getirmesidir. Bu yapılanma; "hekimin mesleğini icra ederken sahip olması gereken özellikler neler olmalıdır?" sorusu temel alınarak oluşturulmuştur. b. Büyük Grup Tartışması: YÜTF-PÇ 2015 Versiyon 1.0, 23 Aralık 2014 tarihinde gerçekleştirilen büyük grup tartışmasında BEKDK iç paydaşların görüşlerine sunulmuştur.

c. Yapılandırılmış Form ile Yazılı Görüş İsteme: 23 Aralık 2014 tarihli toplantıdan sonra daha etkin bir geri bildirim alabilmek ve toplantiya katılamayan iç paydaşlara da ulaşmak amacıyla YÜTF-PÇ 2015 Versiyon 1.0 için yazılı görüş istenmiştir. Bu amaçla kullanılan yapılandırılmış bir form hem program çıktılarının ana çatısına yönelik görüş belirtilebilecek hem de gözden geçirme ve düzeltmelerin YÜTF-PÇ 2011 ile karşılaştırılmasına olanak sağlayacak şekilde hazırlanmıştır.

d. Küçük Grup Tartışmaları: Tüm bu çalışmalardan elde edilen veriler 1şığında BEKDK-UG, YÜTF-PÇ 2015 Versiyon 1.0'a son halini verilmiştir.

B. YÜTF Program Çıktıları 2015 Versiyon 2.0 Çalışmaları:

a. Küçük Grup Tartışmaları: BEK-DK-UG Hedef 2. bağlamında öncelikle YÜTF-PÇ 2011 ile karşılaştırması yapılacak ulusal ve uluslararası dokümanlar (Tablo 2.) belirlenmiştir.

Belirlenen ulusal ve uluslararası dokümanlarda yer alıp YÜTF-PÇ 2011'de yer almayan program çıktıları tespit edilmeye çalışılmıştır. $\mathrm{Bu}$ amaçla kelime ve kelime öbeklerinden anahtar sözcükler oluşturulup, bu anahtar sözcükler üzerinden dokümanların YÜTFPÇ 2011 ile karşılaştırmasına gidilmiştir. $\mathrm{Bu}$ karşılaştırma sonucu YÜTF-PÇ 2015 içinde yer alması önerilen yeterlikler Tablo 3.'de gösterilmiştir. 
Tablo 2. YÜTF-PÇ 2011 ile karșılaștırması yapılan ulusal ve uluslararası dokümanlar

1. UÇEP Tıp Fakültesi Mezunları İçin Ulusal Yeterlikler Çerçevesi Önerisi 2014

2. The Tuning Project (MEDICINE) Learning Outcomes for Undergraduate Medical Education in Europe - 2008

3. Scottish Doctor Learning Outcomes for the Medical Undergraduate in Scotland: A Foundation for Competent and Reflective Practitioners - 2009

4. Tomorrow's Doctors Outcomes and Standards for Undergraduate Medical Education in UK - 2009

5. The Draft CanMEDS Physician Competency Framework in Canada - 2015

Tablo 3. Ulusal ve uluslararası dokümanlar ile karşılaştırma sonucu YÜTF-PÇ 2015 'te yer almak üzere iç paydașlara önerilen yeterlikler.

1. Gerekli/uygun profesyonel tutumlar (sayg1, hasta otonomisi, hastanın karar verme sürecine katılımı, empati, adanmışlık, fedakarlık, hastanın gereksinimleri önceleme, önyargısız yaklaşım)

2. Çoklu kültürlü topluluklarda tıp uygulamaları (farklı görüşler, kültürler, inançlara saygi)

3. Toplumdaki dezavantajlı durumlara/gruplara yaklaşım (engelli, çocuklar, yalnız yaşlılar, cinsiyet açısından dezavantajlılar, öğrenme güçlüğü olanlar, mental hastalığı olanlar vb)

4. Öz farkındalık (hekimin kendisi için; eleștirilere açık olma, kendini değerlendirme, kendi yeterlilik ve sınırlannın farkında olma)

5. Hekimin kendi fiziksel mental sağlığını koruma ve geliştirmesi (stresli koşullar, yaşam şekli, diyet ,egzersiz)

6. Hekimin profesyonel öz motivasyonu

7. Sağlık hizmet kalitesinin sürekli gelişimini sağlama ve hasta güvenliği

8. Hasta merkezli sağllk hizmeti sunma 
b. Anketle Veri Toplama: Yapılan karşılaştırma sonucunda YÜTF-PÇ 2011'de yer almadığı tespit edilen yeterlikler üzerinde çalışılmış, bu yeterlikler yazılı ifadelere dönüştürülmüş ve bu ifadelerin yer aldığı bir anket formu oluşturularak iç paydaşların değerlendirmesine sunulmuştur.

c. Küçük Grup Tartışmaları: Anket verilerinin analizi sonucunda BEK-DK-UG YÜTF-PÇ 2015 Versiyon 2.0'a son halini verilmiştir.

\section{YÜTF Program Çıktıları 2015 Versiyon 3.0 Çalışmaları:}

a. Yazılı ve sözlü görüş isteme: YÜTF-PÇ 2015 Versiyon 2.0 elektronik ortamda ve basilı doküman olarak iç paydaşlara sunulmuş ve yazılı ya da sözlü görüş belirtmeleri istenmiştir.

b. Küçük Grup Tartışmaları: BEK-DK-UG bu çalışmalar sonucu YÜTF-PÇ 2015 Versiyon 3.0'a son halini vermiştir.

D. YÜTF Program Çıktıları 2015 Versiyon 4.0 Çalışmaları:

a. Süreçten sürekli bilgilendirme: YÜTF-PÇ 2015 Versiyon 3.0 elektronik ortamda ve basılı doküman olarak dış paydaşlara gönderilmiştir.

b. Çalıştay: 9 Mart 2015 tarihinde yapılan çalıştaya 21 iç paydaş ve 12 kurumsal diş paydaş temsilcisi katılmıştır. Öncelikle YÜTFPÇ revizyon süreci ve bu amaçla yapılan çalışmalar paylaşılmıştır. Daha sonra iç ve dış paydaşların birlikte çalışması için oluşturulmuş 5 grupta küçük grup çalışmasına geçilmiştir. 5 küçük grupta YÜTF-PÇ 2015 Versiyon 3.0'ın bölümleri üzerine ayrı ayrı çalışılmıştır. $\mathrm{Bu}$ çalışma yapılandırılmış bir form (Form 1.) üzerinden yapılmış, küçük grupların "Program çıktısının, 6 yıllık tıp eğitimini tamamlayan bir tıp fakültesi mezununun sahip olması gereken özellikler arasında yer alması" konusu üzerine tartışmaları sağlanmıştır. Gelen tüm görüşler kurum adı belirtilerek yapılandırılmış formun ilgili bölümüne elektronik ortamda kaydedilmiştir. Küçük grup çalışmaları tamamlandıktan sonra elde edilen sonuçlar çalıştayın tüm katılımcılarına sunulmuştur.

c. Anketle Veri Toplama: Çalıştay sonunda tüm katılımcılar "Yeditepe Üniversitesi Tıp Fakültesi Mezuniyet Öncesi Tıp Eğitimi Programı (YÜTF-MÖTEP) Bologna Süreci Danışma Kurulu, Program Çıktıları Revizyon Çalıştayı, 2015 Anket Formu'nu doldurmuşlardır.

d. Küçük Grup Tartışmaları: BEK-DKUG, YÜTF-PÇ 2015 Versiyon 3.0 küçük grup tartışmalarından elde edilen veriler değerlendirilmek üzere küçük grup tartışmaları düzenlemiştir. Mart 2015 içinde 3-5 öğretim üyesinin katılımı ile gerçekleştirilen 1-3 saat süren 4 toplantı ile YÜTF-PÇ 2015 Versiyon 4.0 ortaya çıkmıştır.

E. YÜTF Program Çıktıları 2015'e son halinin verilmesi:

a. YÜTF-PÇ 2015 Versiyon 4.0, sırasıyla YÜTF Müfredat Kurulu, Program Geliştirme Kurulu ve Fakülte Kurulunun onaylanmasından sonra YÜTF-PÇ 2015 nihai halini almıştır.

F. YÜTF Program Çıktıları 2015'in duyurulması: YÜTF-PÇ 2015 tüm iç ve dış paydaşlara, YÜTF WEB (http://med.yeditepe.edu. tr/YUTF-MOTEP) sitesi üzerinden İngilizce ve Türkçe olarak duyurulmuştur. 


\section{A. YÜTF-PÇ 2015 Versiyon 1.0 Çalışmaları} Sonucunda Elde Edilen Bulgular: BEK-DK-UG Hedef 1. (Gözden geçirme: PÇ'nın gerek varsa sadeleştirilmesi, yeterlik yazımına uygun olarak yeniden yazılması, UÇEP 2014'ün önerdiği yeterlikler çerçevesine uygun hale getirilmesi.) bağlamında elde edilen sonuçlar; YÜTF-PÇ 2011'de yer alan 47 program çıktısindan;
a. 5 PÇ öğrenim hedefleri içine dahil edildi.
b. 14 PÇ yeterlik yazım kurallarına göre yeniden düzenlendi.
c. 3 PÇ fiillerinde değişiklik yapıldı.
d. 25 PÇ aynen korundu.

Program çıktılarının ana çatısı, "hekimin mesleğini icra ederken sahip olması gereken özellikler neler olmalıdır?" sorusundan yola çıkarak, şu üç başlık altında toplanmıştır:
1. Hekimin sahip olması gereken temel donanımlar.

2. Hekimin sahip olması gereken değerler ve yaklaşımlar.

3. Hekimin kişisel gelişimini sürdürmesi için sahip olması gereken özdeğerler.

Hekimin günlük çalışma pratiği içinde yaptıkları bu şekilde belirlendikten sonra üç aşamalı bir düzeylendirmeye gidilmiştir.

B. YÜTF-PÇ 2015 Versiyon 2.0 Çalışmaları Sonucunda Elde Edilen Bulgular:

Ulusal ve uluslararası dokümanlarla yapılan karşılaştırma sonucunda tespit edilen yeterliklere yönelik ifadeler için oluşturulan anketten elde edilen verilerin Tablo 4'te gösterilmiştir. 


\begin{tabular}{|c|c|c|c|c|c|}
\hline \multirow[b]{3}{*}{ Program Çıktılarına Yönelik İfadeler } & \multicolumn{5}{|c|}{$\begin{array}{l}\text { Önerilen ifadelerin iç paydaşlar tarafindan } 2014 \mathrm{PC} \\
\text { revizyonunda yer almasını kabul gōrme oranları } \\
(\mathrm{N}=19)\end{array}$} \\
\hline & 1 & 2 & 3 & 4 & 5 \\
\hline & $\begin{array}{l}\text { (Kesinlikle } \\
\text { yer almasm) }\end{array}$ & $\begin{array}{c}\text { (Yer } \\
\text { almasin) }\end{array}$ & $\begin{array}{c}\text { (Fikrim } \\
\text { yok) }\end{array}$ & (Yer alsm) & $\begin{array}{l}\text { (Kesinlikl } \\
\text { e yer } \\
\text { alsin) }\end{array}$ \\
\hline \multirow{2}{*}{$\begin{array}{l}\text { 1. Gerekli/uygun profesyonel tutumlar (saygı, } \\
\text { hasta otonomisi, hastanın karar verme } \\
\text { sürecine katılımı, empati, adanmışlık, } \\
\text { fedakarlık, hastanın gereksinimleri } \\
\text { önceleme, önyargısız yaklaşım) * }\end{array}$} & & & & $\begin{array}{c}2 \\
(\% 10)\end{array}$ & $\begin{array}{c}17 \\
(\% 90)\end{array}$ \\
\hline & & & & \multicolumn{2}{|c|}{$\% 100$} \\
\hline \multirow{2}{*}{$\begin{array}{l}\text { 2. Coklu kültürlü topluluklarda tıp } \\
\text { uygulamalan (farklı görüşler, kültürler, } \\
\text { inançlara saygı)** }\end{array}$} & \multirow{2}{*}{$\begin{array}{c}1 \\
(\% 5)\end{array}$} & \multirow{2}{*}{$\begin{array}{c}1 \\
(\% 5)\end{array}$} & \multirow{2}{*}{$\begin{array}{c}4 \\
(\% 21)\end{array}$} & $\begin{array}{c}2 \\
(\% 11)\end{array}$ & $\begin{array}{c}11 \\
(\% 58)\end{array}$ \\
\hline & & & & \multicolumn{2}{|c|}{$\% 69$} \\
\hline \multirow{2}{*}{$\begin{array}{l}\text { 3. Toplumdaki dezavantajlı } \\
\text { durumlara/gruplara yaklaşım (engelli, } \\
\text { çocuklar, yalnız yașlılar, cinsiyet açısından } \\
\text { dezavantajlılar, ögrenme güçlüğü olanlar, } \\
\text { mental hastalığı olanlar vb) * }\end{array}$} & & & \multirow[t]{2}{*}{$\begin{array}{c}3 \\
(\% 16)\end{array}$} & $\begin{array}{c}3 \\
(\% 16)\end{array}$ & $\begin{array}{c}13 \\
(\% 68)\end{array}$ \\
\hline & & & & \multicolumn{2}{|c|}{$\% 84$} \\
\hline \multirow{2}{*}{$\begin{array}{l}\text { 4. Ōz farkındalık (hekimin kendisi için; } \\
\text { eleștirilere açı olma, kendini } \\
\text { değerlendirme, kendi yeterlilik ve ve } \\
\text { sinırlarının farkında olma) * }\end{array}$} & & & $\begin{array}{c}5 \\
(\% 26)\end{array}$ & $\begin{array}{c}3 \\
(\% 16)\end{array}$ & $\begin{array}{c}11 \\
(\% 58)\end{array}$ \\
\hline & & & & \multicolumn{2}{|c|}{$\% 75$} \\
\hline \multirow{2}{*}{$\begin{array}{l}\text { 5. Hekimin kendi fiziksel mental sağlığını } \\
\text { koruma ve geliștirmesi (stresli koşullar, } \\
\text { yaşam șekli, diyet, egzersiz) * }\end{array}$} & & \multirow[t]{2}{*}{$\begin{array}{c}1 \\
(\% 5)\end{array}$} & \multirow{2}{*}{$\begin{array}{c}3 \\
(\% 16)\end{array}$} & $\begin{array}{c}3 \\
(\% 16)\end{array}$ & $\begin{array}{c}12 \\
(\% 63)\end{array}$ \\
\hline & & & & \multicolumn{2}{|c|}{$\% 79$} \\
\hline \multirow[t]{2}{*}{ 6. Hekimin profesyonel öz motivasyonu * } & & \multirow{2}{*}{$\begin{array}{c}2 \\
(\% 11)\end{array}$} & \multirow{2}{*}{$\begin{array}{c}1 \\
(\% 5)\end{array}$} & $\begin{array}{c}3 \\
(\% 16) \\
\end{array}$ & $\begin{array}{c}13 \\
(\% 68) \\
\end{array}$ \\
\hline & & & & \multicolumn{2}{|c|}{$\% 84$} \\
\hline \multirow{2}{*}{$\begin{array}{l}\text { 7. Sağlık hizmet kalitesinin sürekli gelişimini } \\
\text { sağlama ve hasta güvenliği * }\end{array}$} & & \multirow{2}{*}{$\begin{array}{c}2 \\
(\% 11)\end{array}$} & \multirow{2}{*}{$\begin{array}{c}1 \\
(\% 5)\end{array}$} & \begin{tabular}{|c|}
5 \\
$(\% 26)$ \\
\end{tabular} & $\begin{array}{c}11 \\
(\% 58) \\
\end{array}$ \\
\hline & & & & \multicolumn{2}{|c|}{$\% 84$} \\
\hline \multirow[t]{2}{*}{ 8. Hasta merkezli sağlik hizmeti sunma * } & & \multirow[t]{2}{*}{$\begin{array}{c}1 \\
(\% 5)\end{array}$} & \multirow{2}{*}{$\begin{array}{c}2 \\
(\% 11)\end{array}$} & $\begin{array}{c}4 \\
(\% 21) \\
\end{array}$ & $\begin{array}{c}12 \\
(\% 63) \\
\end{array}$ \\
\hline & & & & \multicolumn{2}{|c|}{$\frac{104}{\%}$} \\
\hline
\end{tabular}


Anketten elde edilen veriler doğrultusunda yeterlik olarak yazılan ifadeler Tablo 5 'de gösterilmiștir.

\section{Tablo 5. İç Paydaşların PÇ 2015 Revizyonunda Yer Almasını Uygun Bulduğu İfadelerin Program C.ıktısı Olarak Yazılması}

- Öncelikle ifadelerin hangi kaynaklardan elde edildiği gösterilmiștir. Kaynak isminin arkasındaki kısım ilgili kaynaktaki bölüm ve sayfayı göstermektedir.

- Daha sonra bu ifadelerin hangi yeterlik alan grubuna, hangi yeterlik alanına atandığı ve yeterlik olarak yazılmış hali gösterilmiștir.

Ifade 1: Gerekli/uygun profesyonel tutumlar (saygl, hasta otonomisi, hastanin karar verme sürecine katulımı, empati, adanmıslık, fedakarlık, hastanun gereksinimleri önceleme, ënyargısız yaklasim)*

* 1 . The Tuning Project (MEDICINE) Learning Outcomes for Undergraduate Medical Education in Europe $-2008 \rightarrow$ pp 16. Outcomes for Medical Professionalism

2. Scottish Doctor Learning Outcomes for the Medical Undergraduate in Scotland: A Foundation for Competent and Reflective Practitioners - 2009 $\rightarrow$ pp26. 3.9 Learning Outcomes for Attitudes, Ethical Understanding and Legal Responsibilities

3. Tomorrow's Doctors Outcomes and Standards for Undergraduate Medical Education in UK $-2009 \rightarrow$ pp25. Outcomes 3 - The doctor as a Professional

4. The Draft CanMEDS Physician Competency Framework in Canada $-2015 \rightarrow \mathrm{pp} 25$. PROFESSIONAL

5. UÇEP Tıp Fakültesi Mezunlan İ̧in Ulusal Yeterlikler Cerçevesi Ōnerisi - $2014 \rightarrow$ pp.89 c)

Profesyonel değerler, davranışlar ve profesyonelliğe yönelik eğitim içeriği

- PÇAG2-Hekimin mesleğini icra ederken sahip olması gereken değerler ve yaklaşımlar $\rightarrow$ Mevcut Yeterlik Alanı Grubu (YAG)

- PÇA2.5 Profesyonel tutum ve davranışlara ilișkin yeterlikler $\rightarrow$ Yeni Yeterlik Alanı (YA) önerisi

- PÇ2.5.1 Hastalara ve meslektaşlarına saygı gösterir. $\rightarrow$ Yeni Yeterlik (Y) önerisi

- PÇ2.5.2 Hastalara ve onların problemlerine bütünsel ve empatik yaklașır. $\rightarrow$ Yeni Yeterlik (Y) önerisi

- PÇ2.5.3 Hasta otonomisine değer verir kendilerini etkileyecek kararlara onları dahil eder. $\rightarrow$ Yeni Yeterlik (Y) önerisi

Ifade 2: Toplumdaki_dezavantailı_durumlara/gnuplara yaklasım (engelli. cocuklar. valnuz yaşlıar, cinsivet açısından dezavantajlılar, ëğrenme güclüğü olanlar, mental hastalığı olanlar $\mathrm{vb})^{*}$

* 1. The Tuning Project (MEDICINE) Learning Outcomes for Undergraduate Medical Education in Europe $-2008 \rightarrow \mathrm{pp} 24$. Ethical and legal principles in medical practice 
3. Tomorrow's Doctors Outcomes and Standards for Undergraduate Medical Education in UK - $2009 \rightarrow$ pp25. Outcomes 3 - The doctor as a Professional

4. The Draft CanMEDS Physician Competency Framework in Canada $-2015 \rightarrow \mathrm{pp} 25$.

PROFESSIONAL

- YAG2-Hekimin mesleğini icra ederken sahip olması gereken değerler ve yaklașımlar $\rightarrow$ Mevcut Yeterlik Alanı Grubu (YAG)

- YA2.5 Profesyonel tutum ve davranışlara ilișkin yeterlikler $\rightarrow$ Yeni Yeterlik Alanı (YA) önerisi

- Y2.5.4 Toplumdaki dezavantajlı gruplar ve durumlar karșısında uygun davranışlar geliștirir ve gösterir. $\rightarrow$ Yeni Yeterlik (Y) önerisi

Ífade 3: Öz farkındalık (hekimin kendisi için; elestirilere açı olma, kendini değerlendirme. kendi yeterlilik ve smırlarının farkında olma)*

* 1. The Tuning Project (MEDICINE) Learning Outcomes for Undergraduate Medical Education in Europe

$-2008 \rightarrow$ pp16. Outcomes for Medical Professionalism, Professional attributes

2. Scottish Doctor Leaming Outcomes for the Medical Undergraduate in Scotland: A Foundation for Competent and Reflective Practitioners $-2009 \rightarrow$ pp33. 3.9 Learning Outcomes for Attitudes, Level 1 'The doctor as a professional', Level 2 - Outcomes for Personal Development, Self-awareness

3. Tomorrow's Doctors Outcomes and Standards for Undergraduate Medical Education in UK $-2009 \rightarrow$ pp25. Outcomes 3 - The doctor as a Professional

4. The Draft CanMEDS Physician Competency Framework in Canada $-2015 \rightarrow$ pp26.

PROFESSIONAL, Commitment to self

5. UÇEP Tıp Fakültesi Mezunlan lçin Ulusal Yeterlikler Cerçevesi Ônerisi $-2014 \rightarrow$ pp. 89 c)

Profesyonel değerler, davranışlar ve profesyonelliğe yönelik eğitim içeriği

- YAG2-Hekimin mesleğini icra ederken sahip olması gereken değerler ve yaklașımlar $\rightarrow$ Mevcut Yeterlik Alanı Grubu (YAG)

- YA2.5 Profesyonel tutum ve davranıșlara ilișkin yeterlikler $\rightarrow$ Yeni Yeterlik Alanı (YA) önerisi

- Y2.5.5 Eleştirilere açık olarak kendi performansını değerlendirir, yeterlilik ve sınırlılıklarının farkına varır. $\rightarrow$ Yeni Yeterlik (Y) önerisi

İfade 4: Hekimin kendi fiziksel mental sağlığımı koruma ve geliștirmesi (stresli koșullar, yaşam sekli.divet_egzersiz)*

* 1. Scottish Doctor Learning Outcomes for the Medical Undergraduate in Scotland: A Foundation for Competent and Reflective Practitioners - 2009 $\rightarrow$ pp33. 3.9 Learning Outcomes for Attitudes, Level 1 'The doctor as a professional', Level 2 - Outcomes for Personal Development, Self-care

2. Tomorrow's Doctors Outcomes and Standards for Undergraduate Medical Education in UK - 2009 $\rightarrow$ pp25. Outcomes 3 - The doctor as a Professional

3. The Draft CanMEDS Physician Competency Framework in Canada - 2015 $\rightarrow$ pp26.

PROFESSIONAL, Commitment to self

- YAG3-Hekimin mesleğini icra ederken kendini güncel tutabilmesi için yapması gerekenler $\rightarrow$ Mevcut Yeterlik Alanı Grubu (YAG)

- YA3.3. Hekimin Kendi Fiziksel ve Mental Sağlığını Korumasına ve 
- Y3.3.2 Stresli koşullarda çalıșmaya özgün, uygun davranıșlar gösterir. $\rightarrow$ Yeni Yeterlik (Y) önerisi

\section{Ifade 5: Hekimin orofesvonel ëz motivasvonu*}

* 1. Scottish Doctor Learning Outcomes for the Medical Undergraduate in Scotland: A Foundation for Competent and Reflective Practitioners - 2009 $\rightarrow$ pp33. 3.9 Learning Outcomes for Attitudes, Level 1 -

'The doctor as a professional', Level 2 - Outcomes for Personal Development, Motivation

- YAG3-Hekimin mesleğini icra ederken kendini güncel tutabilmesi için yapması gerekenler $\rightarrow$ Mevcut Yeterlik Alanı Grubu (YAG)

- YA3.3. Hekimin Kendi Fiziksel ve Mental Sağlığını Korumasına ve Geliștirmesine İliş̧kin Yeterlikler $\rightarrow$ Mevcut Yeterlik Alanı (YA)

- Y3.3.3 Öz motivasyon faktörlerini kullanır. $\rightarrow$ Yeni Yeterlik (Y) önerisi

\section{Ifade 6: Sağlık hizmet kalitesinin sürekli_gelisimini_sağlama ve hasta güvenliø̆j*}

* 1. Soottish Doctor Learning Outcomes for the Medical Undergraduate in Scotland: A Foundation for Competent and Reflective Practitioners - 2009 $\rightarrow$ pp31. 3.11 Learning Outeomes for The Role of the Doctor within the Health Service, Level 1 - 'The doctor as a professional', Level 2 - Outcomes for The Role of the Doctor within the Health Service

2. Tomorrow's Doctors Outcomes and Standards for Undergraduate Medical Education in UK $-2009 \rightarrow$ pp28. Outcomes 3 - The doctor as a Professional, 23 Protect patients and improve care.

3. The Draft CanMEDS Physician Competency Framework in Canada $-2015 \rightarrow$ pp6. PROFESSiONAL, Commitment to the profession

- YAG2-Hekimin mesleğini icra ederken sahip olması gereken değerler ve yaklașımlar $\rightarrow$ Meveut Yeterlik Alanı Grubu (YAG)

- YA2.5 Profesyonel tutum ve davranışlara ilişkin yeterlikler $\rightarrow$ Yeni Yeterlik Alanı (YA) önerisi

- Y2.5.6 Hasta güvenliği ve sağlık kalitesinin geliştirilmesi için sorumluluk alır. $\rightarrow$ Yeni Yeterlik $(\mathrm{Y})$ önerisi

\section{İfade 7: Hasta merkezli_sağllk hizmetisunma*}

* 1. Scottish Doctor Learning Outcomes for the Medical Undergraduate in Scotland: A Foundation for Competent and Reflective Practitioners - 2009 $\rightarrow$ pp12. 3.1 Learning Outcomes for Clinical Skills, Level 1 - 'What the doctor is able to do', Level 2 - Outcomes for Clinical Skills, pp16. 3.4 Learning Outcomes for Patient Management, Level 1 - 'What the doctor is able to do', Level 2 - Outcomes for Patient Management

2. Tomorrow's Doctors Outcomes and Standards for Undergraduate Medical Education in UK - $2009 \rightarrow$ pp25. Outcomes 3 - The doctor as a Professional

3. The Draft CanMEDS Physician Competency Framework in Canada - 2015 $\rightarrow$ pp9. MEDICAL

EXPERT, pp12. COMMUNICATOR

- YAG1-Hekimin mesleğini icra ederken sahip olması gereken temel donanımlar $\rightarrow$ Mevcut Yeterlik Alanı Grubu (YAG)

- YA1.1.Klinik Yeterlikler $\rightarrow$ Mevcut Yeterlik Alanı (YA)

- Y1.1.15.Hasta yönetiminde hasta merkezli yaklașım gösterir. $\rightarrow$ Yeni Yeterlik (Y) önerisi 
C. YÜTF Program Çıktılan 2015 Versiyon 4.0 Çalışmaları Sonucunda Elde Edilen Bulgular: 9 Mart 2015 tarihinde yapılan çalıștaydaki küçük grup çalıșmaları sonucu elde edilen bulgulara örnekler Tablo 6'da gösterilmiştir.

Tablo 6. 9 Mart 2015 tarihinde yapılan çalıștaydaki küçük grup çalıșmaları sonucu elde edilen bulgulara örnekler.

PÇAG1.Hekimin Mesleğini İcra Ederken Sahip Olması Gereken Temel Donanımlar

PÇA1.1.Klinik Yeterlikler

PÇ1.1.1.Klinik durumlarla ilgili en sık görülen veya en önemli klinik

belirtileri, bulguları ve ortaya çıkıs mekanizmalarını tanır.

Uygundur $\checkmark$

Görüş ve öneriler

i. BA (Fakülte Cerrahi Bilimler Temsilcisi): PC içinde yer alan "en" kelimelerinin çıkarılıp düzenlenmesini önerdi.

ii. AT (Kamu Hastaneleri Birliği Temsilcisi): Birinci basamak hekimini tanımlaması açısından uygun.

iii. AU (TAHUD temsilcisi): AH bakış açısını yansıttığından ülke sağlık hizmetleri sunumuna uygun buldum.

PÇ1.1.3.Genel ve soruna yönelik fizik muayene yapar.

Uygundur $\checkmark$

Görüș ve öneriler

i. BA: Fizik kelimesinin kaldırılıp sadece muayene kalmasını önerdi.

ii. AU: Genel ve soruna yönelik fizik ve mental muayene şeklinde ayrı yazılmasını önerdi.

iii. AT: PÇ'leri genişletmek yerine daha net ve açık olmalı. Birinci basamağa yönelik olarak hekimin neleri kesin olarak yapması gerektiği tanımlanmalı. PÇ'nin bu șekilde kalması uygundur. İlk 4 program çıktısı olduğu gibi kalsin.

PÇ1.1.4.Öykü ve fizik muayene bulgularını doğru yorumlar. 


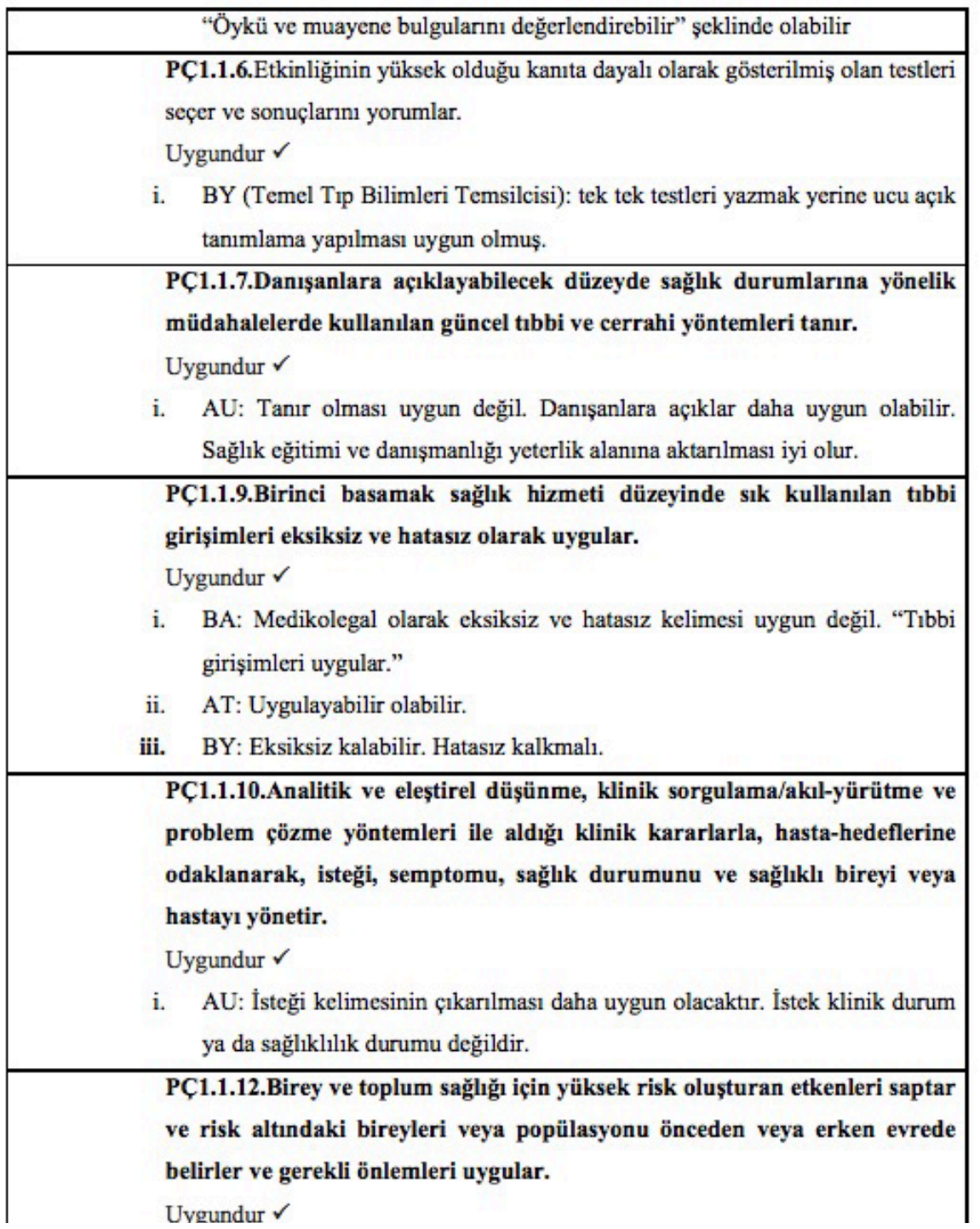


iii. UึA (Temel Bilimler Temsilcisi) : Uygular yerine alır kelimesi uygun.

iv. AT: Örneğin aşı. Uygular ya da uygulanmasını organize eder olmalı. Sağlık personelini yöneten de hekimdir. 14'ün alt başlğı olarak yer alabilir. Birincil ikincil ve üçüncül koruma 14 te açıklanmış. 14'ün altına eklenebilir.

v. AU: Gerekli uygulamaları yapar. Koruyucu sağlık hizmetlerinde erken tanı uygulamaları da var. "gerekli uygulamaları yapar ya da yerine getirir" uygun.

PÇ1.1.13.Birinci basamak sağık hizmetinde, birey, aile ve toplum yönelimli, kolay ulaşılabilir, bütüncül ve koordine, sürekli, kapsamlı, gizlilik ilkelerine dayalı, koruyucu ve tedavi edici hekimlik uygulamaları yapar.

Uygundur $\checkmark$

i. AT: 12. 13. $14^{\prime}$ te bazı kavramlar tekrarlanmıs ve birbirinin içine girmiş. 14 , 12 yi tam ve 13'ü kısmi kapsıyor gibi bu bakımdan tekrar düzenlenmeli.

ii. AU: 13. Zaten koruyucu sağlı hizmetlerini açıklamıș. 12 14'ün öğrenim hedeflerinde yer alabilir. 13 ayrı bir p̧ olarak kalmalı. Bu çıktı fakülte öğrencisinin nasıl bir hekim olması gerektiğini anlatan bir tanımdır ayn kalmalıdır. 1214 'ün altında yer alabilir. Nasıl uygulanacağına dair aynıca alt düzeyde yazilabilir.

iii. EO: 13 çok uzun

\section{PÇ1.1.15. Hasta yönetiminde, hasta merkezli yaklaşım gösterir.}

Uygundur $\checkmark$

i. AU: Hasta merkezli kelimesi yerine birey merkezli olmalı. Sağlıklı kişilerde kapsanmış olur. 


\section{Revizyon Çalışmasının Sonucunda Elde}

\section{Edilen Bulgular:}

YÜTF Program Çıktıları 2015'in son halinde 3 Program Çıktısı Alanı Grubu (PÇAG), 14 Program Çıktısı Alanı (PÇA) ve 43 Program Çıktısı (PÇ) yer almaktadır. YÜTF Program Çıktıları 2015'e http://med.yeditepe.edu.tr/sites/default/files/prog_cik_2015_son.pdf adresinden ulaşılabilmektedir.

\section{TARTIŞMA ve SONUÇ}

YÜTF-PÇ, iç ve dış paydaşların etkin katılımı ile hekimden güncel beklentiler ve toplumun sağlik beklentilerinde yaşanmakta olan değişiklikler bağlamında gözden geçirilmiştir. Bu revizyon çalışması hem yeterliklerin kurallara uygun olarak yazılması yönünden teknik bir süreci hem de içeriğe ilişkin düzenlemeleri kapsamaktadır. Sürecin başında amaçlanan, sağlık hizmeti bağlamında toplum yönelimli, hasta hekim ilişkisi bağlamında ise hasta merkezli ve biyopsikososyal yaklaşım, program çıktılarının arka planında korunmuştur.

Süreç içinde dış paydaşların yüksek katılımına azami önem gösterilmiş, sadece yazılı olarak değil telefon ve e-posta yolu ile de süreçten bilgilendirme sağlanmıştır. Sürece öğrenci katılımı tıp eğitimi sürecini temsilen her sınıftan bir temsilci dahil ederek gerçekleştirilmiştir. Öğrenciler çalıştay programına da katılmışlardır. Süreç içinde iç paydaşların sürece katılımı Kurumun BEK-DK üyeleri ile sınırlı kaldığ 1 izlenmiştir. YÜTF Program Çıktıları 2015'in duyurulmasının etkin bir şekilde yapılması ve iç paydaşlar açısından farkındalığın üst düzeyde sağlanması için çalı̧̧malar yapılmıştır.

Süreç içinde YÜTF'de mezuniyet öncesi eğitimin organizasyonundan ve yürütülmesinden sorumlu tüm kurulların azami katılımına önem verilmiştir. Sürecin açık olarak izlenen tarafının haricinde bu çıtıların eğitim programına nasıl yansıtılacağı ile ilgili fikri tartışmalar sürekli devam etmiştir.

Gelinen noktada YÜTF Mezuniyet Öncesi Eğitim Programının, yatay ve dikeyde entegre üç ana alanda (Temel Donanımlar Eğitimi, Değerler ve Yaklaşımlar Eğitimi, Özdeğerler Eğitimi) yeniden yapılandırılması, minör ve majör müfredat değişiklikleri ile ilgili hedeflenenlerin ve UÇEP 2014 uyumlaştırma çalışmasının bu bağlamda ele alınması gibi kurumsal kararlar alınması sürecin önemli katkılarındandır.

Bir diğer önemli katkı eğitim programının uygulayıcıları (iç paydaşlar-öğretim üyesi, öğrenci) ile eğitim programının sonuçlarından etkilenenlerin (dış paydaşlar) bir araya gelmesi, aralarında hekimden beklenenler açısından ortak fikirler üretmeleri olmuştur. Eğitim programlarının geliştirilmesinde bu analizin yapılmasının oldukça önemli olduğunu düşünüyoruz.

Tıp fakültelerinin kendi eğitim programlarında yaptıkları geliştirici uygulamaları paylaşmaları diğerleri için iyi örnekler oluşturmaktadır. Bu bakımdan çalışmamızın eğitim programlarını gözden geçirecek diğer tıp fakülteleri için rehber olma niteliği taşıyacağını düşünmekteyiz. 


\section{KAYNAKLAR}

1. Harden J R Crosby M H Davis M Friedman RM. AMEE Guide No. 14: Outcome-based education: Part 5-From competency to meta-competency: a model for the specification of learning outcomes. Med Teach. 1999;21(6):546-52.

2. Albanese MA, Mejicano G, Mullan P, Kokotailo P, Gruppen L. Defining characteristics of educational competencies. Med Educ. 2008 Mar;42(3):248-55.

3. Palés J, Cardellach F, Estrach M, Gomar C, Gual A, Pons F, Bombí JA. Defining the learning outcomes of graduates from the medical school at the University of Barcelona (Catalonia, Spain). Med Teach. 2004 May;26(3):23943.

4. Ramesh JC, Radhakrishnan A, Nurjahan MI, Khuzaiah RA, Chen PC.Experience of developing an Outcome-Based Curriculum at the International Medical University, Malaysia. Japanese Medical Education Today. 2004. http:// www1.gifu- u.ac.jp/ medc_arc/jmet/gencho/ ramesh/outcomes-pub.pdf (erişim 09.04.2015)

5. Davis MH1, Amin Z, Grande JP, O’Neill AE, Pawlina W, Viggiano TR, Zuberi R. Case studies in outcome-based education. Med Teach. 2007 Sep;29(7):717-22. 